\title{
Imitation and communication skills development in children with pervasive developmental disorders
}

\author{
This article was published in the following Dove Press journal: \\ Neuropsychiatric Disease and Treatment \\ 17 June 2009 \\ Number of times this article has been viewed
}

\begin{abstract}
Andrea De Giacomo'
Claudia Portoghese

Domenico Martinelli ${ }^{2}$

Isabella Fanizza'

Luciano L'Abate ${ }^{3}$

Lucia Margari'

'Child Neurological and Psychiatric Unit, Department of Neurological and Psychiatric Sciences, University of Bari, Italy; ${ }^{2}$ Department of Biomedical Science and Oncology, University of Bari, Italy; ${ }^{3}$ Department of Psychology, Georgia State University
\end{abstract}

Correspondence: Lucia Margari Sezione di Neuropsichiatria Infantile, Dipartimento di Scienze Neurologiche e Psichiatriche, Università degli Studi, Azienda Ospedaliera Policlinico, Piazza Giulio Cesare CP 70124, Bari, Italia $\mathrm{Tel}+39805478520$

Fax +3980 5478532

Email i.margari@neurol.uniba.it

\begin{abstract}
This study evaluates the correlation between failure to develop spontaneous imitation and language skills in pervasive developmental disorders. Sixty-four children between the age of 3 and 8 years were assessed using the Autism Diagnostic Interview-Revised (ADI-R), the Childhood Autism Rating Scale (CARS), and the Autism Diagnostic Observation Schedule (ADOS), as well as direct observation of imitation. The sample was subdivided into a verbal and a nonverbal group. Analysis of mean scores on the CARS "imitation" items and of ADI-R "spontaneous imitation" and "pointing to express interest" revealed a statistically significant difference between verbal and nonverbal groups, with more severe impairment/higher scores in the nonverbal than the verbal group. These results suggest that nonverbal children have specifically impaired imitation and pointing skills.
\end{abstract}

Keywords: autism, imitation, communication, language, pointing

\section{Introduction}

Several studies have provided strong evidence of an imitation deficit in autism, ${ }^{1-10}$ but the specific nature of this deficit remains unclear. Interesting neurophysiological studies ${ }^{11}$ discovered "mirror neurons" in macaque monkey and a similar system of "mirror neurons" in humans. ${ }^{12,13}$ It is plausible that the mirror neuron system may be involved in imitation in typically developing individuals, and hence also provide the neurological basis for imitation deficits in the spectrum of autism disorders. Moreover, the location of these neurons in the equivalent of Broca's area suggests that shared meanings form the basis of communicative movements, gesture and speech, that all originate from the firing of these mirror neurons, ${ }^{14}$ supporting a close relationship between movement and language. ${ }^{15}$

Few studies have explored the possible connection between failure to develop spontaneous imitation of actions and poor language abilities in autistic children, and these yielded conflicting results. ${ }^{16-22}$

The goal of the present study was to describe the relation between the development of spontaneous imitation skills and communication in a sample of children affected by autism disorders (AD) and pervasive developmental disorder not otherwise specified (PDDNOS), to investigate whether failure of spontaneous imitation and pointing can affect language skills and if so, what the implications are for treatment.

\section{Participants and methods}

Our study focuses on 64 children (55 males, 9 females) aged from 3 to 8.9 years (mean age 4.1) referred to the Child Neurological and Psychiatric Unit of Bari 
University Hospital for symptoms related to autistic spectrum disorders. Exclusion criteria included the presence of neurological disorders of known etiology, major physical abnormalities, and serious head injury.

In accordance with the DSM-IV-TR ${ }^{23}$ criteria, 34 children, 29 males and 5 females, aged from 3.2 to 6.4 years (mean age 4.1) were diagnosed with an $\mathrm{AD}$ at the time of the observation, and 30 children, 26 males and 4 females, aged from 3 to 8.9 years (mean age 4.1) showed symptoms of a PDDNOS. None of the children took medicine. Diagnoses were made by child neuropsychiatrists with a specific experience of assessment of autism spectrum disorders and were corroborated by clinical observation and objective evaluation tests.

Diagnostic evaluation comprised a physical and neurological examination, a general laboratory investigation, and magnetic resonance imaging (MRI) to assess exclusion criteria. All children were assessed through direct free observations and diagnostic instruments: Autism Diagnostic Interview-Revised (ADI-R), ${ }^{24}$ Autistic Diagnostic Observation Schedule (ADOS), ${ }^{25}$ the Childhood Autism Rating Scale (CARS), ${ }^{26,27}$ Leiter R International Performance Scale Revised-Visualization and Reasoning Battery (Leiter-R), ${ }^{28}$ and Vineland Adaptive Behavior Scale (VABS). ${ }^{29}$

During the observation, the child was also presented with opportunities to imitate simple actions with real objects. All CARS and ADI-R imitation scores were supported by structured observation of imitation by trained child neuropsychiatrists.

\section{ADI-R}

The child's parents or caregivers were interviewed with the ADI-R, administered by a trained neuropsychiatrist. This instrument is a standardized, structured interview for caregivers of individuals with autism, which provides a diagnostic algorithm for the ICD10 and DSM-IV-TR definition of autism. The ADI-R evaluates three areas of functioning: Reciprocal Social Interaction Domain (RSI), Communication Domain (C), Repetitive and Stereotyped Behavior Domain (RSB). On the basis of the score on each of the three areas, the ADI-R allows two different diagnostic subcategories to be diagnosed: "autism" when the cut-off values are reached or exceeded in all three domains (RSI cut-off $=10 ; \mathrm{C}$ cut-off $=7-8$; RSB cut-off $=3$ ) and evidence of a developmental abnormality is present before the age of 36 months, PDDNOS when the cut-off values are not reached in all three areas or differ from childhood autism criteria in terms of age of onset or when the cut-off values of at least two areas are not reached.
Different cut-offs were applied in the Communication Domain according to whether the participants were verbal $(\mathrm{V})$ or nonverbal $(\mathrm{NV})$ (V cut-off for autism $=8$; NV cut-off for autism =7). "Verbal", according to the ADI-R protocol, means able to make "functional use of spontaneous, echoed or stereotyped language that, on a daily basis, involves phrases of three words or more that, at least sometimes, include a verb and that is comprehensible to other people." 24

\section{ADOS}

ADOS module 1 was used for children without phrase speech and module 2 for children with phrase speech. ADOS allows two different diagnostic subcategories to be diagnosed: "autism" when the cut-off values are reached or exceeded in the communication domain (comm) and social domain (soc): $($ comm. $\bmod 1 / 2$ cut-off $=4 / 5$; soc $\bmod 1$ cut-off $=7 / 6$; com+soc cutoff $=12 / 12$ ) and PDDNOS when the cut-off values are reached or exceeded in the communication domain (comm) and social domain (soc) and language (comm $\bmod 1 / 2$ cut-off $=2 / 3$; soc $\bmod 1$ cut-off $=4 / 4$; comm + soc cutoff $=7 / 8$ ).

\section{CARS}

Children were rated according to the CARS, based on behavioral observation and interaction with the examiner and parents. This clinical evaluation of behavior is based on interaction and observation, originally developed as an observational instrument with the aim of identifying children with autism, as differentiated from other developmental disorders. Participants' behaviors were rated on each of 15 items from 1 (age-appropriate behavior) to 4 (severely autistic behavior). These items examine socioemotional and interaction skills, language and communication skills, response to sensory information. According to the CARS manual, autism is defined by a score of $\geq 30$ points. Total scores of 30 to 36.5 indicate mild-moderate autism, and scores of 37 and above indicate severe autism. The CARS evaluation was completed by an independent qualified child neuropsychiatrist, blinded to the ADI-R and ADOS-G diagnosis.

\section{Leiter- $R$}

The Leiter-R scale was used to obtain an estimate of the children's cognitive function. This cognitive evaluation was performed by physicians with qualified child neuropsychiatry experience. This scale was developed as a nonverbal intelligence measurement tool to assess 
children, adolescents and young adults from age 2 years, 0 months to 20 years, 11 months, who could not be reliably and validly assessed with traditional intelligence tests. This test is relatively easy to administer and to respond to. It does not require proficiency in perceiving, manipulating, and reasoning with words or numbers or using any other materials traditionally identified as "verbal". All instructions are adapted to a nonverbal format. Because of these features, this scale is widely utilized for the assessment of the intellectual function of children with PDD, above all those that cannot be tested with standard intelligence tests, because it overcomes the obstacle of impairment in communication skills, in attention and in behavior observed in these children. ${ }^{30}$

\section{Communication skills assessment}

On the basis of direct observation, semistructured play sessions, CARS "Verbal Communication" item scores and ADI-R item "overall level of language" values, we subdivided our sample into a group of nonverbal participants and a group of verbal participants. The nonverbal group consisted of 33 children with a CARS "Verbal Communication" score 3 (moderately abnormal verbal communication) or 4 (severely abnormal verbal communication) and with an ADI-R item "overall level of language" score 1 (no functional use of three word phrases in spontaneous, echoed or stereotyped speech, but using speech on a daily basis with at least five different words in the last month) or two (fewer than five words total and/or speech not used on a daily basis). ADOS module 1 was applied in these children.

The verbal group consisted of 31 children with a CARS "Verbal Communication" score 1 (normal verbal communication, age- and situation-appropriate) or 2 (mildly abnormal verbal communication) and with an ADI-R item "overall level of language" score 0 (functional use of spontaneous echoed or stereotyped language that, on a daily basis involves phrases of three words or more, that at least sometimes include a verb, and is comprehensible to other people). ADOS module 2 was administered to these children. The nonverbal group consisted of 21 children with $\mathrm{AD}$ and 12 children with PDDNOS, while the verbal group consisted of 13 children with $\mathrm{AD}$ and 18 children with PDDNOS.

Moreover, one item of the ADI-R "pointing to express interest" in the Communication Domain was chosen for analysis in both the verbal and nonverbal group, graded as follows: 0 , spontaneously points; 1 , makes some attempt to express interest by pointing; 2 , he/she only rarely points; 3 , he/she doesn't point.

\section{Imitation skills assessment}

One item from the ADI-R, "spontaneous imitation of actions" in the Communication Domain and one item from the CARS, "imitation", was selected for analysis in both the verbal and nonverbal group, corroborated by structured imitation observation. The item "spontaneous imitation of actions" from the ADI-R was graded as follows: 0: spontaneously imitates; 1: some indication of spontaneous imitation; 2: limited imitation; 3: very rare or no spontaneous imitation.

The item "imitation" from the CARS was rated as follows: 1, appropriate imitation (the child imitates sounds, words, and movements the same way as a normal child of the same age); 2, mildly abnormal imitation (frequently the child imitates simple behaviors like clapping or sounds. Rarely the child imitates only after a request and with some delay); 3, moderately abnormal imitation (the child imitates only sometimes and only if the adult is very insistent and helps him. Imitation is often delayed); 4, severely abnormal imitation (the child rarely imitates or imitation of sounds, words, and movements is absent, despite requests and help from an adult).

During the imitation observation, the child was presented with opportunities to imitate simple actions (the act of knocking at the doors), action with real objects, to take turns playing with toys (flowers, a car, mug, aeroplane), random "imaginary" objects and to set up a doll's birthday party. Imitation observation was graded as follows: 0, imitation of action on objects; 1, partial imitation of action on objects; 2 , no imitation of action on objects.

\section{Cognitive assessment}

A nonverbal IQ was obtained using the Leiter-R scale, which was completed in only 27 children: 14 children diagnosed with $\mathrm{AD}$ and 13 diagnosed with PDDNOS, 23 males and 4 females, whereas it was not possible to test the other children using standard intelligence tests due to their poor compliance.

\section{Data analysis}

Analyses of mean scores on the CARS "imitation" item and "spontaneous imitation" and "pointing to express interest" items on the ADI-R were performed with one-way analyses of variance (ANOVA) to evaluate differences between the verbal and nonverbal groups and between verbal and nonverbal children affected by AD and by PDDNOS. To demonstrate the relationship between impaired imitation and lower verbal skills a logistic regression model was used. 
Data were tabulated and analyzed using SPSS software (v. 11.0.4 for MAC-OS-X 10.4.8; SPSS Inc., Chicago, IL, USA).

\section{Results}

We studied 64 patients: 34 (29 males, 5 females) affected by AD, 30 ( 26 males, 4 females) by PDDNOS. Mean age in the $\mathrm{AD}$ group was $4.1 \pm 0.8$ years versus $4.1 \pm 1.2$ years in the PDDNOS group (Table 1).

The mean ADI-RSI was $18.4 \pm 5$ in AD and $12.5 \pm 5.8$ in PDDNOS. The mean ADI-C was $11.6 \pm 2.5$ in $\mathrm{AD}$ versus $8.9 \pm 2.9$ in PDDNOS. The mean ADI-RSB was $4.8 \pm 1.1$ in $\mathrm{AD}$ and $3.4 \pm 2$ in PDDNAS. Mean rate of discovery of disturbed development before 36 months was $4 \pm 0.8$ in AD versus $3.1 \pm 1.4$ in PDDNOS. The mean CARS was $36.1 \pm 4.7$ in $\mathrm{AD}$ versus $29.4 \pm 3.4$ in PDDNOS (Table 1).

There were 31 children (13 AD and 18 PDDNOS) in the verbal group and 33 children (21 AD and 12 PDDNOS) in the nonverbal group. There was a significant difference ( $F=24.8 ; p<0.001)$ between the means of the CARS total score in the verbal group (30 \pm 4$)$ and the nonverbal group $(35.7 \pm 4.9)$. There was a significant difference $(F=45.4$; $\mathrm{p}<0.001)$ between the mean total score for the ADI-R RSI in the verbal group (10.5 \pm 4$)$ and the nonverbal group (18.6 \pm 5.3$)$. Instead, there was no a significant difference between the mean total score for the ADI-R RSB in the verbal group ( $4 \pm 1.9)$ and nonverbal group (3.9 \pm 1.7$)$. There was a significant difference $(\mathrm{F}=11.8 ; \mathrm{p}=0.001)$ between the ADI-R means total score A (abnormality of development evident at or before 36 months) in the verbal group (2.9 \pm 1.5$)$ and the nonverbal group $(4 \pm 0.8)$.

The mean CARS imitation score was $1.7 \pm 0.5$ in the verbal group and $2.8 \pm 0.7$ in the nonverbal group; there was a significant difference $(\mathrm{F}=47.8 ; \mathrm{p}<0.001)$ between these two groups.

The logistic regression model (including age, diagnosis, and CARS) showed that the higher the CARS score for imitation (worse imitation) the lower the likelihood that the child would have developed "verbal language" (odds ratio $[\mathrm{OR}]=0.65,95 \%$ confidence interval $[\mathrm{CI}]$ : 0.52-0.84; $\mathrm{p}=0.001)$. No difference was reported for age and diagnosis $(\mathrm{p}>0.05)$.

The mean ADI-R imitation score was $0.7 \pm 0.7$ in the verbal group and $1.6 \pm 0.6$ in the nonverbal group; there was a significant difference $(\mathrm{F}=30.4 ; \mathrm{p}<0.001)$ between these two groups.

The logistic regression model (including age, diagnosis, and CARS) showed that increased ADI-R values for imitation (worse imitation) decreased the probability of being able to use "verbal language" $(\mathrm{OR}=0.13,95 \% \mathrm{CI}$ : $0.04-0.38$; $\mathrm{p}<0.001$ ).

The mean ADI-R pointing score was $0.35 \pm 0.6$ in the verbal group and $1.4 \pm 0.6$ in the nonverbal group; there was a significant difference $(F=40.7 ; p<0.001)$ between these two groups. The mean observed imitation pointing score was $0.7 \pm 0.7$ in the verbal group and $1.5 \pm 0.6$ in the nonverbal group, showing a significant difference $(\mathrm{F}=22.6$; $\mathrm{p}<0.05$ ) (Table 2).

In the $\mathrm{AD}$ group, there was a significant difference $(\mathrm{F}=24.4 ; \mathrm{p}<0.001)$ between the means of the CARS imitation score in the verbal group $(1.9 \pm 0.6)$ versus the nonverbal group $(3 \pm 0.6)$; there was a significant difference $(F=9.7 ; p<0.05)$ between the means of the ADI-R imitation score in the verbal group $(1 \pm 0.7)$ versus the nonverbal group $(1.8 \pm 0.6)$; there was a significant difference $(F=10.5$; $\mathrm{p}<0.05)$ between the means of the ADI-R pointing score in the verbal group $(0.6 \pm 0.8)$ versus the nonverbal group (1.4 \pm 0.7$)$ (Table 3).

In PDDNOS, there was a significant difference ( $\mathrm{F}=17.5$; $\mathrm{p}<0.001)$ between the means of the CARS imitation score in the verbal group $(1.5 \pm 0.4)$ versus the nonverbal group $(2.5 \pm 0.8)$; there was a significant difference $(\mathrm{F}=17.5 ; \mathrm{p}<0.001)$ between the means of the ADI-R imitation score in the verbal group $(0.4 \pm 0.5)$ versus the nonverbal group (1.3 \pm 0.6$)$; there was a significant difference ( $F=35 ; p<0.001$ ) between the means of the ADI-R pointing score in the verbal group $(0.2 \pm 0.3)$ versus the nonverbal group (1.2 \pm 0.6$)$ (Table 4$)$.

Of the 27 children tested with the Leiter-R, 14 children belonged to the verbal group and 13 to the nonverbal group. The mean IQ score for the sample was $78.0 \pm 17.9$. The mean nonverbal IQ for the verbal group was $84.4 \pm 21.1$ and for the nonverbal group was $71.2 \pm 10.8$, with no statistical difference $(\mathrm{F}=2.33 ; \mathrm{p}>0.05)$. The results of ANOVA with the IQ as covariate confirm that the correlation found seems to be independent of the child's cognitive ability, among the children who underwent the Leiter-R.

\section{Discussion}

In children with autism, imitation skill and gestural joint attention have been found to correlate with early verbally responsive abilities. ${ }^{16,17}$ Longitudinal studies found that imitation and joint attention, measured early, were associated with later expressive language ability. ${ }^{7,18,20-22}$ Moreover, Stone and colleagues ${ }^{19}$ demonstrated that imitation of body movements, but not of actions on objects, was associated 
Table I Demographic characteristics, ADI-R and CARS mean scores of the total sample $(n=64)$

\begin{tabular}{|c|c|c|c|}
\hline Variable & AD children & PDDNOS children & p-value \\
\hline $\mathrm{N}$ & 34 & 30 & \\
\hline Boy/girl & $29 / 5$ & $26 / 4$ & \\
\hline \multicolumn{4}{|c|}{ Age (years) } \\
\hline M & 4.1 & 4.1 & \\
\hline SD & 0.8158 & 1.2998 & \\
\hline \multicolumn{4}{|c|}{ Age distribution (years) } \\
\hline 3 & 14 & 17 & \\
\hline 4 & 15 & 4 & \\
\hline 5 & 3 & 8 & \\
\hline 6 & 2 & - & \\
\hline 7 & - & - & \\
\hline 8 & - & 1 & \\
\hline \multicolumn{4}{|c|}{ ADI-R, ADOS, and CARS scores } \\
\hline \multicolumn{4}{|c|}{ ADI-RSI (cut-off for autism = I0) } \\
\hline M & 18.4 & 12.5 & $\mathrm{p}<0.001$ \\
\hline SD & 5 & 5.8 & \\
\hline \multicolumn{4}{|c|}{$\begin{array}{l}\text { ADI-C (NVC cut-off for autism = 7; } \\
\text { VC cut-off for autism = 8) }\end{array}$} \\
\hline M & 11.6 & 8.4 & $\mathrm{p}<0.001$ \\
\hline SD & 2.5 & 2.9 & \\
\hline \multicolumn{4}{|c|}{ ADI-R-RSB (cut-off for autism = 3) } \\
\hline M & 4.8 & 3.4 & $\mathrm{P}<0.00 \mathrm{I}$ \\
\hline SD & I.I & 2 & \\
\hline \multicolumn{4}{|c|}{$\begin{array}{l}\text { ADI-R Developmental defic } \\
\text { evident before } 36 \text { months } \\
\text { (cut-off for autism }=1 \text { ) }\end{array}$} \\
\hline M & 4 & 3.1 & $p=0.001$ \\
\hline SD & 0.8 & $\mathrm{I} .4$ & \\
\hline
\end{tabular}

ADOS module $1 / 2$ comm. (cutoff for autism $=4 / 5$; cutoff for autism spectrum disorder $=2 / 3$ )

$M$

SD

ADOS module $1 / 2$ soc.

(cutoff for autism = 7/6; cutoff for autism spectrum disorder $=4 / 4$ )

\begin{tabular}{|c|c|c|c|}
\hline M & 9.0 & 4.7 & $\mathrm{p}<0.001$ \\
\hline SD & 1.7 & 0.7 & \\
\hline \multicolumn{4}{|c|}{$\begin{array}{l}\text { ADOS module } 1 / 2 \text { comm }+ \text { soc. } \\
\text { (cutoff for autism = } 12 / / 2 \text {; cutoff for } \\
\text { autism spectrum disorder } 7 / 8 \text { ) }\end{array}$} \\
\hline M & 15.5 & 7.2 & $\mathrm{P}<0.00 \mathrm{I}$ \\
\hline SD & 3.3 & 1.0 & \\
\hline \multicolumn{4}{|c|}{ CARS (cut-off for autism = 30) } \\
\hline M & 36.1 & 29.4 & $\mathrm{P}<0.00 \mathrm{I}$ \\
\hline SD & 4.7 & 3.4 & \\
\hline
\end{tabular}

Abbreviations: ADI-R,Autism Diagnostic Interview-Revised;ADOS, Autism Diagnostic Observation Schedule; CARS, Childhood Autism Rating Scale; Cl, confidence interval; comm, Communication Domain; NVC, Nonverbal and Verbal Communication Domain; RSI, Reciprocal Social Interaction Domain; RSB, Repetitive and Stereotyped Behavior Domain; SD, standard deviation; soc, Social Domain. 
Table 2 Mean imitation and pointing items scores for the ADI-R and CARS of the Verbal and Nonverbal Groups

\begin{tabular}{|c|c|c|c|c|c|c|c|c|}
\hline & \multicolumn{3}{|c|}{ Verbal group $(\mathbf{N}=3 \mathrm{I})$} & \multicolumn{3}{|c|}{ Nonverbal group $(\mathbf{N}=33)$} & \multirow[b]{2}{*}{$\mathbf{F}$} & \multirow[b]{2}{*}{$\mathbf{p}$} \\
\hline & $\mathbf{M}$ & 95\% Cl for Mean & SD & $\mathbf{M}$ & $95 \% \mathrm{Cl}$ for Mean & SD & & \\
\hline CARS Imitation & 2.07 & I.468-1.887 & 0.570 & 2.803 & $2.54-3.05$ & 0.7174 & 47.845 & $<0.05$ \\
\hline ADI-R Imitation & 0.71 & $0.46-0.96$ & 0.693 & 1.64 & I.40-1.87 & 0.653 & 30.369 & $<\mathbf{0 . 0 5}$ \\
\hline Observed Imitation & 1.54 & $0.43-0.98$ & 0.66 & 0.77 & I.30-I.78 & 0.73 & 22.6 & $<0.05$ \\
\hline ADI-R Pointing & 0.35 & $0.13-0.58$ & 0.608 & 1.36 & $1.13-1.60$ & 0.653 & 40.777 & $<0.05$ \\
\hline
\end{tabular}

Note: There is a significant difference for all variables.

Abbreviations: ADI-R,Autism Diagnostic Interview-Revised; CARS, Childhood Autism Rating Scale; Cl, confidence interval; SD, standard deviation.

with later expressive language skills, while Charman and colleagues ${ }^{18}$ demonstrated that imitation of action on objects at the age of 20 months was associated with language ability in the fourth year of life.

Our results highlight that a reduced or totally absent spontaneous imitation of actions in AD and PDDNOS children is related to reduced or totally absent communication skills. Vice versa, good imitating of actions is related with good communication. We have shown that most children with impaired spontaneous imitation of actions and pointing demonstrated by high scores for the relative items in the ADI-R, CARS and by spontaneous and partly structured observation of imitation also show very limited expressive language. In the literature, only Charman and colleague ${ }^{20}$ have previously compared imitation and language skills in children meeting the diagnostic criteria for PDDNOS. Our data, in accordance with those reported in the Charman and colleagues ${ }^{20}$ study, show that poorer imitation is more common in nonverbal children affected by AD and PDDNOS. This finding suggests that the correlation found between imitation and verbal communication could be independent of the specific diagnostic categories, being instead a feature of all autistic spectrum disorders, and featuring only quantitative differences according to the clinical diagnostic category. This association could be explained by the fact that during the prelinguistic stage of child development, communication is based on nonverbal behavior such as gaze, facial expression and body language (including pointing) to communicate their needs, wishes, and social intentions and gesture often conveys information that is not conveyed in the speaker's words. ${ }^{31,32}$ Furthermore, during the first stages of verbal skill development, language always accompanies the child's play and only after age two do children abandon their own gestures in favor of the exclusive use of verbal language, when they can manage it in a more mature way. ${ }^{33,34}$ Our findings seem to support the concept that failure to develop imitation skills could affect the whole communication domain, both gesture and verbal, in these disorders.

In our sample, 27 children were tested with the Leiter-R the mean nonverbal IQ for the verbal group was 84 versus 71 for the nonverbal group. This difference was not statistically significant. This result is consistent with some longitudinal studies in which language at follow-up was not positively associated with a nonverbal IQ. ${ }^{17,20,35}$ By contrast, other studies in autistic children found different intensities of interaction and imitation deficits according to their cognitive developmental level and nonverbal cognitive ability and earlier communication skills were consistently strong predictors of later language acquisition). ${ }^{22,36}$

As pointed out in the introduction, several authors discussing modern neuropsychological interpretations have assumed that mirror neurons act as a bridge between perceived action and language. ${ }^{12,15,37}$ Several studies have reported evidence for an impaired mirror neuron system in individuals with autism spectrum disorders. ${ }^{38-43}$ It is important to note that

Table 3 Mean imitation and pointing items scores for the ADI-R and CARS of the children with AD

\begin{tabular}{|c|c|c|c|c|c|c|c|c|}
\hline & \multicolumn{3}{|c|}{ AD Verbal group $(N=13)$} & \multicolumn{3}{|c|}{ AD Nonverbal group $(N=2 I)$} & \multirow[b]{2}{*}{$\mathbf{F}$} & \multirow[b]{2}{*}{$\mathbf{p}$} \\
\hline & $\mathbf{M}$ & $95 \% \mathrm{Cl}$ for Mean & SD & $M$ & 95\% Cl for Mean & SD & & \\
\hline CARS Imitation & 1.92 & $1.536-2.310$ & 0.6405 & 2.976 & $2.712-3.240$ & 0.5804 & 24.437 & $<0.05$ \\
\hline ADI-R Imitation & 1.08 & $0.62-1.54$ & 0.760 & 1.81 & $1.54-2.08$ & 0.602 & 9.738 & $<0.05$ \\
\hline ADI-R Pointing & 0.62 & $0.15-1.08$ & 0.768 & 1.43 & I.I2-I.74 & 0.676 & 10.475 & $<0.05$ \\
\hline
\end{tabular}

Note: There is a significant difference for all variables

Abbreviations: ADI-R, Autism Diagnostic Interview-Revised; CARS, Childhood Autism Rating Scale; Cl, confidence interval; SD, standard deviation. 
Table 4 Mean imitation and pointing items scores for the ADI-R and CARS of the children with PDDNOS

\begin{tabular}{|c|c|c|c|c|c|c|c|c|}
\hline & \multicolumn{3}{|c|}{ PDDNOS Verbal group $(\mathrm{N}=18)$} & \multicolumn{3}{|c|}{ PDDNOS Nonverbal group $(\mathrm{N}=12)$} & \multirow[b]{2}{*}{$\mathbf{F}$} & \multirow[b]{2}{*}{$\mathbf{p}$} \\
\hline & $M$ & 95\% Cl for Mean & SD & $\bar{M}$ & 95\% Cl for Mean & SD & & \\
\hline CARS Imitation & 1.500 & $1.274-1.726$ & 0.4537 & 2.500 & $1.958-3.042$ & 0.8528 & 17.530 & $<0.05$ \\
\hline ADI-R Imitation & 0.44 & $0.19-0.70$ & 0.511 & 1.33 & $0.92-1.75$ & $0.65 I$ & 17.483 & $<0.05$ \\
\hline ADI-R Pointing & 0.17 & $0.53-1.07$ & 0.383 & 1.25 & $0.86-1.64$ & 0.622 & 35.052 & $<0.05$ \\
\hline
\end{tabular}

Note: There is a significant difference for all variables.

Abbreviations: ADI-R, Autism Diagnostic Interview-Revised; CARS, Childhood Autism Rating Scale; Cl, confidence interval; SD, standard deviation.

a human mirror neuron is involved in imitation and probably in language.

In accordance with this developing body of literature, our data suggest that in autistic children, a disconnection disorder may be present, negatively affecting the physiological process of communication development. The present findings provide further evidence of an association between an imitation deficit and poor communication development in children with PDDs, supporting the new concept of a neuropsychological implication of the mirror neuron system in these deficits. Therefore, the lack of imitative capacities in autistic and PDDNOS children could be responsible for a reduced or totally absent development of communicative skills.

Our study's limit is that the imitation was assessed by spontaneous and partly structured observation, bearing in mind that at present no structured validated imitation tests are available.

The correlation between imitation and communication skills can be useful for planning rehabilitation treatment for these children in fact, some studies have emphasized the importance of imitation in behavioral intervention to improve communication abilities in young autistic children. ${ }^{21,44}$ In particular, Ingersoll and Schreibman ${ }^{45}$ demonstrated, by means of a naturalistic behavioral technique in children with autism, that teaching object imitation increases social communication behaviors including language. These results support the effectiveness of intervention to teach imitation as a means of fostering language development. The results of the present study have implications on early intervention goals: imitation may be an important target for early intervention in nonverbal autistic children.

\section{Disclosure}

The authors report no conflicts of interest in this work. The limit of the study is that the imitation was assessed with a spontaneous observation and partly structured. No structured imitation tests have been validated to the best of our knowledge.

\section{References}

1. Baron-Cohen S. Social and pragmatic deficits in autism cognitive or affective? J Autism Dev Disord. 1988;18:379-402.

2. Rogers SJ, Pennington BF. A theoretical approach to the deficits in infantile autism. Dev Psychopathol. 1991;3:137-162.

3. Smith IM, Bryson SE. Imitation and action in autism: a critical review. Psychol Bull. 1994;116:259-273.

4. Rogers SJ, Bennetto L, McEvoy R, Pennington BF. Imitation and pantomime in high-functioning adolescents with autism spectrum disorders. Child Dev. 1996;67:2060-2073.

5. Roeyers H, Van Oost P, Bothuyne S. Immediate imitation and joint attention in young children with autism. Dev Psychopathol. 1998;10: 441-450.

6. Whiten A, Brown J. Imitation and the reading of other minds: Perspectives from the study of autism normal children and non-human primates. In: Braten S, editor. Intersubjective communication and emotion in ontogeny: a sourcebook. New York: Cambridge University Press; 1998. p. $260-280$.

7. Stone WL, Ousley OJ, Littleford CD. Motor imitation in young children with autism: What's the object? J Abnorm Child Psychol. 1997;25:475-485.

8. Striano T, Tomasello M, Rochat P. Social and object support for early symbolic play. Dev Sci. 2001;4:442-455.

9. Ingersoll B, Schreibman L, Tran QH. Effect of sensory feedback on immediate object. Imitation in children with autism. J Autism Dev Disord. 2003;33:673-683.

10. Rogers SJ, Hepburn SL, Stackhouse T, Wehner E. Imitation performance in toddlers with autism and those with other developmental disorders. J Child Psychol Psychiatry. 2003;44:763-781.

11. Di Pellegrino G, Fadiga L, Fogassi L, Gallese V, Rizzolatti G. Understanding motor events: A neurophysiological study. Exper Brain Res. 1992;91:176-180.

12. Rizzolatti G, Fadiga L, Gallese V, Fogassi L. Premotor cortex and the recognition of motor actions. Cogn Brain Res. 1996;3:131-141.

13. Rizzolatti G, Craighero L. The mirror-neuron system. Ann Rev Neurosci. 2004;27:169-192.

14. Rizzolatti G, Arbib MA. Language within our grasp. Trends Neurosci. 1998;21:188-194.

15. Rizzolatti G, Fogassi L, Gallese V. Cortical mechanism subserving object grasping and action recognition: a new view on the cortical motor functions. In: Gazzaniga M, editor. The Cognitive Neurosciences. Cambridge, MA: MIT Press; 2000. p. 539-552.

16. Dawson G, Adams A. Imitation and social responsiveness in autistic children. J Abnorm Child Psychol. 1984;12:209-226.

17. Mundy P, Sigman M, Kasari C. A longitudinal study of joint attention and language development in autistic children. J Autism Dev Disord. 1990;20:115-128.

18. Charman T, Baron-Cohen S, Swettenham J, Baird G, Cox A, Drew A. Testing joint attention, imitation and play as infancy precursors to language and theory of mind. Cogn Dev. 2000;15:481-498.

19. Stone WL, Yoder PJ. Predicting spoken language in children with autistic spectrum disorders. Autism. 2001;5:341-361. 
20. Charman T, Baron-Cohen S, Swettenham J, Baird G, Cox A. Predicting language outcome in infants with autism and pervasive developmental disorder. Int J Lang Commun Disord. 2003;38:265-285.

21. Toth K, Munson J, Meltzoff AN, Dawson G. Early predictors of communication development in young children with autism spectrum disorder: Joint attention, Imitation, and Toy Play. J Autism Dev Disord. 2006;36:993-1005.

22. Thurm A, Lord C, Lee LC, Newschaffer C. Predictors of language acquisition in preschool children with autism spectrum disorders. J Autism Dev Disord. 2007;37:1721-1734.

23. American Psychiatric Association. Diagnostic and Statistical Manual of Mental Disorders. 4th ed. text revision. Washington, DC: APA; 2000.

24. Lord C, Rutter M, Le Couteur A. Autism Diagnostic Interview- Revised: A revised version of a diagnostic interview for caregivers of individuals with possible pervasive developmental disorders. J Autism Dev Disord. 1994;24:659-685.

25. Lord C, Risi S, Lambrecht L, et al. The ADOS-G (Autism Diagnostic Observation Schedule-Generic): a standard measure of social communication deficit associated with autism disorders. J Autism Dev Disord. 2000;30:205-223.

26. Schopler E, Reichler RJ, Renner BR. The Childhood Autism Rating Scale (CARS). Los Angeles, CA: Western Psychological Services; 1988.

27. Prizant B. Review of the Childhood Autism Rating Scale. In: Kramer JJ, Conoley JC, Murphy LL, editors. The Eleventh Mental Measurements Yearbook. Lincoln: University of Nebraska Press; 1992. p. 170-171.

28. Roid GM, Miller LJ. Leiter International Performance Scale-Revised: Examiners manual. Wood Dale, IL: Stoelting Co; 1997.

29. Carter AS, Volkmar FR, Sparrow SS, et al. The Vineland Adaptive Behavior Scales: supplementary norms for individuals with autism. J Autism Dev Disord. 1988;28:287-302.

30. Tsanasis KD, Dartnall N, Cicchetti D, Sparrow SS, Klin A, Volkmar FR. Le Scale Leiter e Leiter-R in bambini con autismo a basso funzionamento. Autismo e disturbi dello sviluppo, 2004;2:311-326.

31. Landa R. Early communication development and intervention for children with autism. Mental Retard Dev Disabil Res Rev. 2007;13:16-25.

32. Ozçalişkan S, Goldin-Meadow S. Gesture is at the cutting edge of early language development. Cognition. 2005;96(3):101-113.

33. McCune-Nicolich L. Toward symbolic functioning: Structure of early pretend games and potential parallels with language. Child Dev. 1981;52:785-797.
34. Meltzoff A, Moore MK. Imitation of facial and manual gestures by human neonates. Science. 1977;198:75-78.

35. Sigman M, Ruskin E. Continuity and change in the social competence of children with autism, Down syndrome and developmental delays. Monogr Soc Res Child Dev. 1999;64:1-114.

36. Receveur C, Lenoir P, Desombre H, Roux S, Barthelemy C, Malvy J. Interaction and imitation deficits from infancy to 4 years of age in children with autism: a pilot study based on videotapes. Autism. 2005;9:69-82.

37. Gallese V, Goldman A. Mirror neurons and the simulation theory of mind-reading. Trends Cogn Sci. 1998;2:493-501.

38. Altschuler EL, Vankov A, Hubbard EM, Roberts E, Ramachandran VS, Pineda JA. Mu wave blocking by observer of movement and its possible use as a tool to study theory of other minds. New Orleans, LA: Poster session presented at the 30th Annual Meeting of the Society for Neuroscience; 2000.

39. Oberman LM, Hubbard EM, McCleery JP, Altschuler EL, Ramachandran VS, Pineda JA. EEG evidence for mirror neuron dysfunction in autism spectrum disorders. Cogn Brain Res. 2005;24: 190-198.

40. Nishitani N, Avikainen S, Hari R. Abnormal imitation-related cortical activation sequences in Asperger's syndrome. Ann Neurol. 2004;55:558-562.

41. Villalobos ME, Mizuno A, Dahl BC, Kemmotsu N, Muller RA. Reduced functional connectivity between V1 and inferior frontal cortex associated with visuomotor performance in autism. Neuroimage. 2005;25:916-925.

42. Theoret H, Halligan E, Kobayashi M, et al. Impaired motor facilitation during action observation in individuals with autism spectrum disorder. Curr Biol. 2005;15:R84-R85.

43. Dapretto M, Davies MS, Pfeifer JH, et al. Understanding emotions in others: mirror neuron dysfunction in children with autism spectrum disorders. Nature Neurosci. 2006;9:28-30.

44. Maurice C, Green G, Luce S. Behavioural intervention for young children with autism. A manual for parents and professionals. Austin TX: Pro-Ed; 1996.

45. Ingersoll B, Schreibman L. Teaching reciprocal imitation skills to young children with autism using a naturalistic behavioural approach: effects on language, pretend play, and joint attention. J Autism Dev Disord. 2006;36:487-505.
Neuropsychiatric Disease and Treatment

\section{Publish your work in this journal}

Neuropsychiatric Disease and Treatment is an international, peerreviewed journal of clinical therapeutics and pharmacology focusing on concise rapid reporting of clinical or pre-clinical studies on a range of neuropsychiatric and neurological disorders. This journal is indexed on PubMed Central, the 'PsycINFO' database and CAS, and is the official

\section{Dovepress}

journal of The International Neuropsychiatric Association (INA). The manuscript management system is completely online and includes a very quick and fair peer-review system, which is all easy to use. Visit http://www.dovepress.com/testimonials.php to read real quotes from published authors. 